\section{Congenital malformations among newborns in Morocco: A retrospective study}

\author{
Adil Elghanmi, ${ }^{1}$ Rachid Razine,2 \\ Mohamed Jou, ${ }^{3}$ Rachid Berrada, ${ }^{4}$ \\ ${ }^{1}$ Centre for Doctoral Studies in Life \\ and Health Sciences, Faculty of \\ Medicine and Pharmacy, Mohammed VI \\ University of Health Sciences (UM6SS), \\ Casablanca; ${ }^{2}$ Laboratory of Public \\ Health, Faculty of Medicine, \\ Mohammed V University, Rabat; \\ 3Service of Obstetrics and Gynecology, \\ Souissi, CHU Rabat; ${ }^{4}$ Faculty of \\ Medicine, Mohammed V University, \\ Rabat, Morocco
}

\section{Abstract \\ Congenital malformations are one of the} leading causes of neonates and infants' mortality and morbidity. The frequency of these congenital malformations varies in different populations. The objective of this study was to find out the prevalence and pattern of congenital malformations in a tertiary teaching hospital in Rabat, Morocco. This four-year retrospective descriptive study was conducted from January 2011 to December 2014. All newborns with congenital malformations diagnosed at birth were included. Mothers and newborn characteristics were analyzed using SPSS 13.0. A total of 706 newborns were noted to have congenital malformation. The prevalence rate was $1.02 \%$. The mean maternal age was $28.8 \pm 7.2$ years. The mean maternal body mass index was $28.1 \pm 6.9 \mathrm{~kg} / \mathrm{m}^{2}$. $13.3 \%$ of the mothers had a history of abortion. The nervous system was the most affected system (19.4\%) followed by the musculoskeletal system $(14.2 \%)$, the chromosomal abnormalities (12.3\%) and the genito-urinary system (10.8\%). Males newborns (57.9\%) had more congenital malformations than females $(40.5 \%)$. The rates for live-births, fetal asphyxia and stillbirths were $75.2 \%$, $7.2 \%$ and $17.3 \%$, respectively. This retrospective study provides recent and detailed data about congenital malformations in a Moroccan region. The result from this study will contribute to the knowledge of congenital malformations in this particular area and hence the supportive preventive policy.

\section{Introduction}

A Congenital malformation is typically defined as any abnormality affecting the structure or function of the body that is present from birth. ${ }^{1}$ Congenital malformations are a global health problem. Every year an estimated of 7.9 million children are born with a serious birth defect, 3.3 million children (under five years) die from birth defects, and 3.2 million who survive may develop a disability later in life. ${ }^{2}$ Furthermore, more than 7000 different congenital malformation have been identified to date. While some are clinically obvious at birth; others may only be diagnosed later in life. ${ }^{3}$ Congenital malformations can be caused by single gene defects, chromosomal disorders, multifactorial inheritance, environmental teratogens and micronutrient deficiencies.

Maternal infections such as rubella, maternal illnesses like diabetes mellitus, iodine and folic acid deficiency, exposure to medicinal and recreational drugs including alcohol and tobacco, certain environmental chemicals, and doses of radiation are all other factors that cause congenital malformations. 4

The prenatal diagnosis of congenital malformation consists of non-invasive techniques such as ultrasonography scan in first or second trimester and maternal serum alpha-fetoprotein measure. Invasive techniques consist of amniocenthesis and chorionic villus sampling.

The treatment and rehabilitation of these children with congenital malformations is very costly, hence the need to identify causative and risk factors and prevent them early where possible is necessary. 5

The prevention of these disorders is available in $60 \%$ of cases. This needs however epidemiological information.

Prevalence studies of congenital anomalies are useful to establish baseline rates, to document changes over time, and to identify clues to the etiology. ${ }^{6}$ Many of the developed countries monitor the prevalence of congenital malformations through registration or surveillance system of fetuses and infants. In addition, international organizations have been established to conduct worldwide surveillance and research into the occurrence and possible causes of congenital anomalies and to establish prevention strategies. ${ }^{6}$

The prevalence of congenital malformations ranges from $1 \%$ to over $4 \%$ depending on the place and population studied. For instance; it ranges from an average of $1.07 \%$ in Japan to $4.3 \%$ in Taiwan. ${ }^{4,5,7}$

In the United States, where most research has been conducted on this subject, a 2-3\% birth prevalence of congenital malformations has been reported. The birth prevalence of congenital malformations in England is $2 \%$ and in South Africa it is
Correspondence: Adil Elghanmi, Centre for Doctoral Studies in Life and Health Sciences, Faculty of Medicine and Pharmacy, Mohammed VI University of Health Sciences (UM6SS), Casablanca, Morocco.

E-mail: aelghanmi@um6ss.ma

Key words: Congenital malformations, Morocco, Neonates, Prevalence, Pattern.

Acknowledgments: The authors want to address special acknowledgement to all the obstetric care givers at the Maternite Souissi, Rabat, Morocco.

Contributions: AE have made substantial contributions to conception and design of the study, acquisition of data, interpretation of data and drafted the manuscript. RR participated in the design of the study and performed the statistical analysis. MJ have made substantial contributions to acquisition of data. RB have been involved in drafting the manuscript and revising it critically. All authors read and approved the final manuscript.

Conflict of interest: The authors declare no potential conflict of interest.

Funding: None

Availability of data and materials: The data that support the findings of this study are available from the corresponding author upon reasonable request

Ethics approval and consent to participate: This research was conducted in accordance with al relevant guidelines and procedures.

Consent for publication: This research doesn't contain any elements that allow the recognition of the patients.

Received for publication: 13 September 2019

Revision received: 30 January 2020

Accepted for publication: 27 February 2020.

This work is licensed under a Creative Commons Attribution NonCommercial 4.0 License (CC BY-NC 4.0).

(C) Copyright: the Author(s), 2020

Licensee PAGEPress, Italy

Pediatric Reports 2020; 12:7405

doi:10.4081/pr.2020.7405

$1.49 \%$. These variations may be explained by social, racial, ecological, and economical influences. ${ }^{8}$ The actual prevalence of congenital malformations in Africa may be different than in the developed world due to differences in genetics and differences in exposures such as infections, while the recognized prevalence may be different for reasons of underreporting, deficiencies in diagnostic capabilities, and poor follow-up for examination for anomalies in the post- 
natal period. The rare studies on congenital malformations in Africa have reported an incidence between $1.5 \%$ and $2.5 \%$ in Egypt and East Africa (Kenya and Uganda) respectively. ${ }^{7}$ In Morocco congenital malformations are an important cause of infant mortality and morbidity and the studies about the prevalence of fetal malformation are rare and about small samples. ${ }^{9}$ This study was designed to determine the prevalence, pattern and factors associated with congenital malformations in a tertiary teaching hospital at Rabat, the capital of Morocco for a 4-year period from January 2011 to December 2014. The result from this study will contribute to the knowledge of congenital malformations in this particular area and hence the supportive preventive policy.

\section{Materials and Methods}

\section{Study area}

The study was conducted at the Maternite Souissi, the obstetrical department of a tertiary teaching hospital of Rabat, Morocco. This is the first teaching unit in the country. It caters to an average 70-80 new antenatal registration per day and 16000 deliveries per year. It includes a region called Rabat sale Zemmour Zear. This region covers approximately 9580 square kilometers. Situated in NorthWestern Morocco, the region has a population of more than 2.3 million people, with both, rural and urban background.

\section{Study population}

To describe the study population, we analyzed the different characteristics of the mother and the newborn. Congenital malformations were defined as obvious anomalies of structure or form and present at birth. All the newborns with congenital malformations were examined by a pediatrician at the delivery room.

The study covers births with gestational age of 22 weeks or greater. Mothers' age was categorized. Mothers body mass index was categorized into 3 groups, normal (18,5-25 kg/m²), overweight $\left(25-30 \mathrm{~kg} / \mathrm{m}^{2}\right)$, and obese $\left(>30 \mathrm{~kg} / \mathrm{m}^{2}\right)$. Other variables include parity status and history of abortion. For the newborn, birth weight was categorized into 3 groups: low birth weight $(<2499$ g), normal birth weight (2500$4199 \mathrm{~g})$ and macrosomia $(>4200 \mathrm{~g})$.

The gestational age was divided into 3 age groups: preterm (22-36 weeks), at term (37-42 weeks) and post term ( $>42$ weeks).

Other variables include life status with Apgar score, gender, fetal presentation and type of delivery. Congenital malformations were categorized according to the International Statistical Classification of Diseases and Related Health Problems 10th Revision (ICD-10) Version for congenital malformations, deformations and chromosomal abnormalities. When two systems were involved, it was recorded as multiple congenital anomalies.

Table 1. Mother's characteristics.

\begin{tabular}{llcc} 
Parameter & & Frequency & Percentage \\
Maternel age & $\leq 19$ & 43 & 6.7 \\
& $19-24$ & 136 & 21.3 \\
& $25-30$ & 145 & 22.7 \\
& $30-35$ & 133 & 20.8 \\
& $35-40$ & 113 & 17.7 \\
BMI kg/m & $>40$ & 68 & 10.7 \\
& Normal $<25$ & 151 & 29.8 \\
& Overweight $25-30$ & 204 & 40.2 \\
Gravida & Obese $>30$ & 152 & 30 \\
& 1 & 310 & 44.7 \\
& 2 & 163 & 23.5 \\
History of abortion & Yes & 221 & 31.8 \\
& No & 94 & 13.3 \\
& & 612 & 86.7 \\
\hline
\end{tabular}

\section{Data analysis}

Data was analyzed using SPSS 13.0. Rates and proportions were calculated with $95 \%$ confidence intervals.

\section{Results}

During this 4-year period, there were 68704 birth delivered at Maternite Souissi, the obstetrical department of a Tertiary teaching hospital of Rabat, the capital of Morocco. Out of this birth number, 706 showed congenital malformations. The prevalence rate of congenital malformations was $1.02 \%$. The mean age of the mothers whose newborn have congenital malformations was $29.8 \pm 7.2$ years. The mean Boy Mass index was $28.1 \pm 6.9$ $\mathrm{kg} / \mathrm{m}^{2}$. In this study, $40.2 \%$ of mothers had overweight and $30 \%$ were obese. Also, $13.3 \%$ of the women had a history of abortion. Table 1 shows maternal characteristics. The nervous system was the most affected system (19.4\%) followed by the musculoskeletal system $(14.2 \%)$, the chromosomal abnormalities $(12.3 \%)$ and the genito-urinary system $(10.8 \%)$. Table 2 shows the frequency and

Table 2. Classifications of congenital malformations according to ICD10.

\begin{tabular}{|c|c|c|c|c|}
\hline Systeme & Frequency & Percentage & $\mathrm{ICD} 10$ & 95\% Confidence Interval \\
\hline Congenital malformations of the nervous system & 137 & 19.4 & Q00-Q07 & $16.6-22.4$ \\
\hline Cleft lip and cleft palate & 43 & 6.1 & Q35-Q37 & $4.4-7.9$ \\
\hline Congenital malformations of the urinary system & 76 & 10.8 & Q60-Q64 & $8.4-13.0$ \\
\hline Congenital malformations and deformations of the musculoskeletal system & 100 & 14.2 & Q65-Q78 & 11.6-16.7 \\
\hline Congenital malformation syndromes predominantly affecting facial appearance & 29 & 4.1 & Q87.0 & $2.7-5.7$ \\
\hline Gastroschisis and other congenital malformations of abdominal wall & 30 & 4.2 & Q79.3 Q79.5 & $2.7-5.8$ \\
\hline Congenital absence, atresia and stenosis of anus without fistula Imperforate anus & 12 & 1.7 & Q42.3 & $0.8-2.8$ \\
\hline Atresia of esophagus without fistula & 14 & 2.0 & Q39.0 & $1.0-3.1$ \\
\hline Chromosomal abnormalities & 87 & 12.3 & Q90-Q91 & $9.8-14.9$ \\
\hline Multiple Congenital malformation, & 111 & 15.7 & & $13.2-18.6$ \\
\hline Other congenital anomalies & 67 & 9.5 & & 7.4-11.8 \\
\hline
\end{tabular}


percentage of congenital malformations according to the ICD 10 . This study shows also that males newborns (57.9\%) had more congenital malformations than females $(40.5 \%)$. Concerning life status at time of delivery, $512(75.2 \%)$ were alive with an Apgar Score >7, 51 (7.2\%) had fetal asphyxia, and $118(17.3 \%)$ were still birth. Table 3 summarizes the characteristics of the congenital malformations.

\section{Discussion}

Congenital malformations are one of the major causes of pregnancy loss, stillbirth, neonatal death, and physical defects and disabilities around the world. 1

The prevalence rate of congenital malformations of $1.02 \%$ obtained in our study is similar to the findings of Swardekar in Oman (1.2\%), ${ }^{10}$ Madi in Kuwait who reported an incidence of $1.25 \%, 11$ and Mashhadi Hussein who reported in Iran a prevalence rate of $1.12 \% .5$ Our prevalence rate was low compared to the results of the European network of population-based registers for the epidemiological surveillance of congenital malformations (EUROCAT) $(2.4 \%) .{ }^{4}$ Prevalence from Nigeria has been reported as $2.7 \%$, Taiwan $164.3 \%$, Bahrain $2.7 \%$ and Saudi Arabia 2.79\%.6,12 Table 4 resumes a comparison of prevalence of congenital malformations in different Arab and African countries. However, any two studies are never comparable in the strict sense of the term because the true prevalence of congenital malformations depends upon many factors like place of study, nature of sample, ethnicity, geographical distribution and socioeconomic status. The mean maternal age (in years) of those with congenital malformations is $29,8 \pm 7.2$. It corresponds to the results of other publications. ${ }^{1,6}$ High incidence of congenital malformations among primi-gravida was reported by our study. In other studies, the incidence of congenital malformations was higher in multiparous. ${ }^{13-15}$ Chromosomal anomalies are known to be the single most common cause of spontaneous abortion. Historically, 50\% of spontaneously expelled aborts have been thought to be chromosomally abnormal.16

An increased risk of karyotypic abnormality identified at the time of prenatal diagnosis is demonstrated in patients with an increasing number of spontaneous miscarriages. ${ }^{17} 13.3 \%$ of women in our study had a history of miscarriage. In this study the most common anomaly was nervous system which is consistent with reports from some African countries, Saudi Arabia, Pakistan and India.7,13 The lack of folic acid supplementation, may explain the increased occurrence of these disorders in our series. Some studies, however, recorded a higher

Table 3. Newborn's characteristics.

\begin{tabular}{llcc}
\hline Parameter & & Frequency & Percentage \\
Gender & Male & 395 & 57.9 \\
& Female & 276 & 40.5 \\
& Genital ambiguity & 11 & 1.6 \\
Gestational age & Preterm & 119 & 17.4 \\
& At term & 549 & 80.4 \\
& Post term & 15 & 2.2 \\
\hline Birthweight & $2.5-4 \mathrm{~kg}$ & 435 & 64.6 \\
& $<2.5 \mathrm{~kg}$ & 175 & 26.0 \\
\multirow{5}{*}{ Fetal presentation } & Cephalic & 53 & 9.4 \\
& Breech & 75 & 85.3 \\
& Transverse & 10 & 12 \\
& Other & 7 & 1.6 \\
\hline \multirow{2}{*}{ Mode of delivery } & Vaginal delivery & 450 & 1.2 \\
& Caesarean delivery & 245 & 64.7 \\
\multirow{2}{*}{ Life status } & Alive & 512 & 35.3 \\
& Stillbirth & 118 & 75.2 \\
& Fetal asphyxia & 51 & 17.3 \\
& & & 7.5 \\
\hline
\end{tabular}

Table 4. Congenital malformations in other countries.

\begin{tabular}{|c|c|c|c|c|}
\hline Author & Country (city) & Prevalence rate & $\begin{array}{l}\text { N. congenital anomalies } \\
\text { (deliveries) }\end{array}$ & Study period \\
\hline Juliet Ndibazza [2] & Entebbe, Uganda & 2.03 & $180(2365)$ & 2003-2005 \\
\hline Herbert A Obu [6] & Enugu, South-East Nigeria & 2.8 & $17 / 706$ & January 2007 and April 2011 \\
\hline Sandeep Sachdeva [3] & Haryana, India & 1.64 & 47 & $\begin{array}{c}\text { Randomly selected } 4 \\
\text { months of a calendar year (2010) }\end{array}$ \\
\hline Mohamed A. El Koumi [4] & Zagazig Governorate, Egypt & 2.5 & $63 / 2517$ & $\begin{array}{l}\text { January } 2011 \text { to } \\
\text { December } 2011\end{array}$ \\
\hline Hossein Mashhadi Abdolahi [5] & Tabriz, northwest of Iran & 1.12 & $254 / 22500$ & 2004-2012 \\
\hline A.G. Tomatır [8] & Denizli, Turkey & 0.29 & $183 / 63159$ & 2000-2004 \\
\hline Shabbir Hussain [13] & Kharian, Pakistan & 7 & $226 / 3210$ & September 2011 to February 2013 \\
\hline Isa Abdi-Rad [19] & Urmia, Northwestern Iran & 1.87 & 264/14121 & January 2001 through June 2005 \\
\hline Sallout [12] & g Fahad Medical City, Saudi Arabia & 2.7 & $217 / 5379$ & March 2005 to February 2007 \\
\hline Sawardekar [10] & Nizwa, Oman & 2.46 & $541 / 21988$ & January 1993 through December 2002 \\
\hline Madi SA [11] & Al Jahra, Kuwait & 12.5 & $97 / 7739$ & January 2000 to December 2001 \\
\hline Al Hosani H* & $\begin{array}{l}\text { nal Congenital Anomalies Register, } \\
\text { United Arab Emirates }\end{array}$ & 0.79 & & 1999-2001 \\
\hline Our study & Rabat, Morocco & 1.02 & $706 / 68704$ & January 2011to December 2014 \\
\hline
\end{tabular}

*Al Hosani H, Salah M, Abu-Zeid H, Farag HM, Saade D. The National Congenital Anomalies Register in the United Arab Emirates. East Mediterr Health J. 2005;11:690-9. 
incidence of musculoskeletal system. . $^{2,4}$

There was no case of cyanotic congenital heart defect at birth noted in this study. Under diagnosis is especially right for congenital heart diseases at birth even in developed countries, as it usually gets detected later after discharge from institution. ${ }^{3}$

The incidence of congenital malformations in our study was higher in male than in female. This is consistent with most studies made around the world. ${ }^{11,18}$ Although, some rare studies have shown a difference with a higher prevalence of congenital malformations among female than male. ${ }^{19} \mathrm{We}$ also found that the rate of congenital malformations in full-term neonates was higher than in preterm neonates. This was in contrast with studies from Nigeria and Pakistan.3,11

In this study, the incidence of congenital malformations was higher among normal weight babies in comparison to the low birth weight babies. Nevertheless, the association of low birth weight and malformations has been well documented in other studies. ${ }^{4}$ In our study, the rate of stillbirth was $17,3 \%$ which is compatible with the studies carried in Iran. ${ }^{11}$ To date, there are no such large epidemiological studies done on major congenital anomalies in Morocco.

In terms of limitations, the current study was based on a hospital delivery unit and, as such, is not representative of the situation in the community at large. A lack of postmortem examination of stillborn infants, and those delivered at home who died in the neonatal period, incomplete follow-up to age one year, and lack of genetic studies; all of these may have resulted in an underestimation of the overall prevalence of congenital anomalies. Moreover, the introduction of advanced techniques such as fetal visualization using ultrasound screening and chromosome microarray testing at birth, would greatly improve the early detection of anomalies in many developing countries. ${ }^{2}$ It is necessary to establish a registry system for congenital anomalies.

A prospective, community-based study is thus desirable.

\section{Conclusions}

The results from this 4-year period study shows that the prevalence of congenital malformations in Maternite Souissi, the obstetrical department of a tertiary teaching hospital of Rabat, the capital of Morocco is $1.02 \%$. This study gives also a view of the pattern of congenital malformations in our country. All results appear to be consistent with similar ones from the studies in other countries. This would give a stimulus for further studies in the subject and a healthcare plan for prevention strategies.

\section{References}

1. Zīle I, Villeruša A. Maternal age-associated congenital anomalies among newborns: a retrospective study in Latvia. Medicina (Kaunas) 2013;49:29-35.

2. Ndibazza J, Lule S, Nampijja M, et al. A Description of Congenital Anomalies Among Infants in Entebbe, Uganda. Birth Defects Research Part A. Clin Mol Teratol 2011;91:857-61.

3. Sachdeva S, Nanda S, Bhalla K, Sachdeva R. Gross congenital malformation at birth in a government hospital. Indian J Public Health 2014;58:54-6

4. El Koumi MA, Al Banna EA, Lebda I. Pattern of congenital anomalies in newborn: a hospital-based study. Pediatr Rep 2013;5:e5.

5. Mashhadi Abdolahi H, Kargar Maher MH, Afsharnia F, Dastgiri S. Prevalence of Congenital Anomalies: A Community-Based Study in the Northwest of Iran. Int Schol Resh Not Pediatr 2014;2014:920940.

6. Obu HA, Chinawa JM, Uleanya ND, et al. Congenital malformations among newborns admitted in the neonatal unit of a tertiary hospital in Enugu, SouthEast Nigeria - a retrospective study. BMC Res Notes 2012;5:177.

7. Mashuda F, Zuechner A, Chalya PL, et al. Pattern and factors associated with congenital anomalies among young infants admitted at Bugando medical centre, Mwanza, Tanzania. BMC Res Notes 2014;7:195.

8. Tomatir AG, Demirhan H, Sorkun HC, et al. Major congenital anomalies: a five-year retrospective regional study in Turkey. Genet Mol Res 2009;8:19-27.

9. Sabiri N, Kabiri M, Razine R, et al.
Congenital malformations risk factors: Prospective study of Rabat Souissi maternity in Morocco. J Pédiatr Puéricult 2013;26:198-203.

10. Sawardekar KP. Profile of major congenital malformations at Nizwa Hospital, Oman: 10-year review. J Paediatr Child Health 2005;41:323-30.

11. Madi SA, Al-Naggar RL, Al-Awadi SA, Bastaki LA. Profile of major congenital malformations in neonates in Al-Jahra region of Kuwait. East Mediter Health J 2005;11:700-6.

12. Sallout BI, Al-Hoshan MS, Attyyaa RA, Al Suleimat AA. Antenatal diagnosis, prevalence and outcome of major congenital anomalies in Saudi Arabia: A hospital-based study. Ann Saudi Med 2008;28:272-6.

13. Hussain S, Asghar I, Sabir MU, et al. Prevalence and pattern of congenital malformations among neonates in the neonatal unit of a teaching hospital. J Pak Med Assoc 2014;64:629.

14. Taksande A, Vilhekar K, Chaturvedi P, Jain M. Congenital malformations at birth in Central India: A rural medical college hospital based data. Indian $\mathrm{J}$ Hum Genet 2010;16:159-63.

15. Gul F, Jabeen M, Khan AS. Frequency of congenital malformations and associated risk factors at Liaqat Memorial Hospital, Kohat. Khyber Med Univ J 2012;4:119-24.

16. Gardner RJM, Sutherland GR. Chromosome abnormalities and genetic counseling, 2nd edition. New York, Oxford University Press, 1996.

17. Bianco K, Caughey AB, Shaffer BL, et al. History of miscarriage and increased incidence of fetal aneuploidy in subsequent pregnancy. Obstet Gynecol 2006;107:1098-102.

18. Sokal R, Tata LJ, Fleming KM. Sex prevalence of major congenital anomalies in the United Kingdom: A national population-based study and international meta-analysis. Birth Defects Research (Part A) 2014;100:79-91.

19. Abdi-Rad I, Khoshkalam M, FarrokhIslamlou HR. The Prevelance at Birth of OvertCongenital Anomalies in Urmia Northwestern Iran. Arch Iran Med 2008;11:148-51. 